\title{
HACIA UNA SEMIÓTICA DEL RELATO DE ACTUALIDAD
}

\author{
TOWARDS A SEMIOTICS OF THE PRESENT
}

\author{
Alfredo Tenoch CID JURADO \\ Universidad Autónoma Metropolitana Xochimilco, México \\ alfredo.cid.jurado@hotmail.com
}

\begin{abstract}
Resumen: El relato de actualidad es un medio recurrente para la comunicación del acontecer cotidiano. Una exploración en su definición, al observarlo desde la semiótica del relato y en distintas manifestaciones, permite conocer su estructura, su estrategia y su comportamiento. Mediante la identificación de relatos considerados de actualidad en su momento, es posible reconocer las estrategias de su funcionamiento y su valor, pero también sus riesgos.
\end{abstract}

Palabras clave: Semiótica del relato. Actualidad. Pandemia. Narración. Historia.

Abstract: The current story is a recurring medium for the communication of daily events. An exploration in its definition, in observing it from the semiotics of the story and in different manifestations, allows us to know its structure, its strategy and its behavior. Through the identification of stories considered current at the time, it is possible to recognize the strategies of their operation, their value but also their risks.

Keywords: Semiotics of narration. Present. Pandemic. Narration. History.

\section{RELATAR EL SUCESO COTIDIANO: RASGOS Y CARCATERÍSTICAS}

El relato de lo sucedido ante un evento de naturaleza trascedente suele heredarse como una historia encapsulada y corroborada, a partir de mecanismos de registro para confrontar una actualidad convertida en hecho histórico. La comunicación inmediata ha sido siempre una necesidad imperante en la transmisión de información $y$, por consiguiente, es el resultado del uso de la tecnología comunicativa a disposición; pero requiere estructuración para ser adecuada a las reglas inherentes de un vehículo expresivo. La inmediatez es un requisito indispensable en la eficacia comunicativa de lo actual y lo relevante, como se observa actualmente en las diversas redes y plataformas de internet. No obstante, al ser relato, ordena, relaciona y transforma acciones y pasiones orientadas con un fin comunicativo. Si el relato es resultado de un acto de configuración del sentido, 
variable en acciones y pasiones, éstas deben ser organizadas en forma concatenada para responder a la acción de la narratividad (Fabbri, 1997). La pregunta entonces es: ¿cómo funciona el mecanismo generador de sentido en los relatos de actualidad para describir un momento sucedido en el pasado inmediato y convertido en sustituto de un suceso marcado por su relevancia para ser conservado?

\section{EL RELATO DE ACTUALIDAD Y SU SEMIÓTICA}

La dimensión semántica del vocablo actualidad condiciona semióticamente el concepto actual como sustitución de algo en lugar de otra cosa. Al conferirle individualidad y personalidad, la actualidad opera como diferenciación para establecer un tipo específico de relato, pues determina la interpretación con respecto a la distancia de los hechos narrados en la perspectiva de su consumo. La actualidad en su dimensión semiótica más amplia califica un hecho acontecido, más si está presente en diversos idiomas con otros vocablos como vehículos lingüísticos: en inglés present, topicality; en francés presente; en italiano attualità, presente. En el uso para referir el tiempo presente, el "algo sucediendo en este momento"; se resalta la "acción sucedida en contemporáneo" por sobre la acción misma que se debe referir, la cual se vuelve automáticamente pasado. Por consiguiente, remite además a sucesos, a acontecimientos producidos en el momento de ser comentados, o bien a las acciones efectuadas en un momento determinado de carácter relativo a su presente. En consecuencia, la suma de esas acciones concatenadas de manera deliberada debe dotar de coherencia a un relato para poder denominarse de actualidad. Las definiciones de diccionario del castellano permiten identificar algunos aspectos, necesarios por su presencia, para poder definir la coherencia y la cohesión de un relato reconocido al interior de esa categoría. En el cuadro aparecen los principales componentes de las definiciones consultadas:

\begin{tabular}{|c|c|c|c|}
\hline & RAE & Martín Alonso (1947) & María Moliner (1988) \\
\hline Origen & & De actual & Cualidad de actual \\
\hline Temporalidad & Un momento dado & Tiempo presente & $\begin{array}{l}\text { Momento o tiempo en } \\
\text { que estamos }\end{array}$ \\
\hline Dimensión & $\begin{array}{l}\text { El común de las } \\
\text { gentes }\end{array}$ & $\begin{array}{l}\text { A las gentes en un } \\
\text { momento dado }\end{array}$ & Interesa o se habla de \\
\hline Cognición & Atrae la atención & $\begin{array}{l}\text { Lo que se contrapone a } \\
\text { lo potencial o virtual }\end{array}$ & $\begin{array}{l}\text { Aquello que interesa o } \\
\text { de lo que se habla ahora }\end{array}$ \\
\hline
\end{tabular}

Tabla 1. Comparación de la dimensión semántica en las definiciones de actualidad en castellano

La actualidad en un relato requiere de un doble valor temporal: el directo y el relativo, "algo sucediendo en este momento" o "algo que sucedió en ese momento". La diferencia reside en cómo se entiende ser "actual", así como en su valor proyectado al pasado; es decir, "en ese momento era actual”. La segunda condición es útil para individuar el comportamiento de los relatos de actualidad, pues la primera requeriría de observar las 
fuentes informativas a cada momento para diferenciar entre las "últimas noticias" a "el día de hoy sucedió...". La actualidad puede poseer una condición relativa, ya que se refiere a un "pensar hacia atrás" como consecuencia de volverse relato (Jedlowski, 2007), aunque alude a un problema de enunciación: donde un enunciado es proferido por un enunciador y dirigido a un enunciatario en condiciones para ser entendido y responder así a la necesidad de conformar el sentido para su comprensión. En tanto que actual, debe superar "la obscuridad del segundo vivido" (Bloch, 1949) para propiciar la comprensión del hecho relatado. El problema de la sustitución semiótica se traslada a otros sistemas, con la variabilidad incluida del doble valor temporal (el directo y el relativo), sobre todo al segundo, al momento de determinar en qué sentido un relato es actual. Tanto en su producción como en sus usos e interpretaciones, al ser respuesta de la denominada inteligencia colectiva (Lévi, 1994), de las multitudes inteligentes (Rheingold, 2002), y al predominio de la realidad virtual por sobre la real (Kerckhove, 1997).

\section{RELATO DE ACTUALIDAD Y SU SEMIÓTICA}

Al aportar a la crítica de los acervos literarios o históricos de una cultura, la vocación semiótica volcada hacia los relatos contribuye a comprender su función comunicativa, su funcionamiento estructural, su capacidad de vehicular significación. Una semiótica cognitiva proyecta la atención hacia la capacidad reguladora del relato en la conformación del conocimiento al orientar la percepción de la realidad. Un relato de actualidad supone así una organización semiótica interna y el uso de estrategias para ordenar los componentes de la narración, garantizándose su comprensión. Ahora bien, tales aspectos proceden de preguntas específicas: cómo funcionan los componentes, cuál es su morfología, cómo estructuran la narración, de qué manera hacen funcionar la cooperación del receptor.

Una semiótica del relato ubica su tarea principal dentro de un proceso de comunicación con una intención específica por comunicar, sin perder de vista la huella cognitiva en los destinatarios. En consecuencia, ubica también los saberes necesarios para su comprensión, aquellos en previa posesión y aquellos adquiridos en su proceso receptivo. La suma de recursos permite observar al relato desde la tensión, las pasiones, la sistémica narrativa y la extra-sistémica, en el traslado de una historia intersemiótica e inclusive en su reproposición. El relato por su temporalidad ofrece perspectivas de interpretación: el tiempo del relato y su organización en función de la trama, el tiempo narrado, el tiempo de su enunciación y el tiempo de su interpretación (Ricoeur, 1983). El relato de actualidad es un presente continuo, el cual lleva una vigencia temporal adecuada al momento de la realización de los actos con respecto a su posterior uso e interpretación (Eco, 1979). En tales condiciones, la acción narrada permanece en continuidad, aún si se observa coordinada con el tiempo pasado para referir hechos acontecidos y con un grado mínimo de conexión con el presente. La temporalidad se traslada entonces a las condiciones de recepción, donde tiempo y espacio intersectan para dar origen a los 
cronotopos (Bajtin, 1989). Con la tarea de volver visibles las condiciones narrativas de la historia para ser apreciadas desde una perspectiva estética, el relato de actualidad muestra un discurrir del tiempo localizado en el espacio. Al interior de un relato coexisten cronotopos varios, pero articulados en conexión con una trama textual, creándose así una atmósfera y un efecto sensible determinado (Bajtín, 1989).

La organización interna hace posible observar la sucesión de acontecimientos reunidos en una sola acción principal para poder acceder al grado de relato (Bremond, 1966). Se identifican sus componentes y su relación interna de acuerdo con el modelo semiótico de análisis: ya sea fábula, trama y discurso, paseos inferenciales o competencia enciclopédica (Eco, 1979, 1994), estructura narrativa y recorrido narrativo (Greimas, 1970), o articulación para referir el significado de la experiencia somática del hombre a través de la conceptual (Courtés 1976). Incluso las formas sistémicas permiten reconocer los límites de configuración textual en sus formas emergentes y en su delimitación de las posibilidades de interpretación. De ese modo, muestran jerarquización, orden y coherencia interna de sus componentes (Lotman, 1970).

Una primera categorización de la ordenación y la clasificación de los relatos de actualidad identifica las expresiones narrativas en sus modalidades de existencia, ya sean orales, escritas, gráficas e incluso gestuales. Las clases narrativas más frecuentes: la mitificación, las cercanías a la epopeya, a la tragedia, al drama o sus equivalentes, se expresan ahora por el gif, el comic o la animación, los micro-relatos visuales o la conversación virtual. Se procede así al reconocimiento del modelo deductivo, a la construcción de un modelo hipotético de descripción del cual derivarían subclases en relatos provenientes del relato de actualidad de lo cotidiano.

\section{RELATO DE ACTUALIDAD Y EL PROCESO DE COMUNICACIÓN}

La característica principal de un relato de actualidad consiste en ser inmediato a los sucesos acontecidos. Ahí reside su importancia posterior para reconstruir los hechos, transformándolos en contenidos y a la manera de adecuarlos para transmitirlos. Un relato identificado por la actualidad de los sucesos y lo contemporáneo a ellos se encuentra en Plinio el Joven, en su descripción de la erupción del volcán Vesubio. Los relatos asumen el formato de dos cartas dirigidas a Tácito: 1) la carta Decimosexta contiene "el famoso relato de la muerte de Plinio Viejo durante la erupción del Vesubio del año 79" y 2) la Vigésima carta, "G. Plinio saluda a su querido Tácito", contiene el relato de la salida de Miseno junto a su madre donde se ajustan al formato de carta como tipo de relato. Es decir, la organización estructural contiene una comunicación dirigida a un alguien, en este caso a Tácito; no es una epístola dirigida a un destinatario ficticio. Al ser solicitada por el destinatario refiere específicamente la organización de los acontecimientos narrados para facilitar su comprensión. Al final de la Decimosexta carta, el mismo Plinio destaca: "una cosa, en efecto, es escribir una carta y otra una obra histórica, una cosa dirigirse a un amigo y otra al mundo entero" (Plinio el Joven, 2007 [Epístolas XVI-XXII]). Para la 
jerarquización de los componentes de su narración, Plinio el Joven coloca las fuentes que nutren la verosimilitud de su relato y procura la autenticidad requerida para garantizar los valores de verdad, a fin de evitar el riesgo de un cuestionamiento paradigmático o de la ruina total del esfuerzo semántico de la historia narrada. Su principal recurso es la autopsia: el "yo vi" (Lozano, 1987), que brinda las condiciones para comprender el valor de verdad del relato de actualidad, pues en el proceso comunicativo se manifiestan las condiciones de comunicabilidad y ahí se instaura la función comunicativa a desarrollar. Tales presencias en las cartas de Plinio el Joven muestran la acción de un relato de actualidad en un funcionamiento adecuado y en la estructuración de la narración en su labor semiótica. Es decir, estar en lugar del hecho narrado. Las cartas de Plinio el Joven llevan una impronta estructurante en la fórmula probada para narrar los hechos a partir de los relatos de Virgilio, Lucrecio, Epicuro y Tito Livio. Se trata del recurso de la imitación por medio de expresiones narrativas usadas como subsistemas de eficacia para garantizar una correcta interpretación en la fruición del relato (Momigliano, 1983). Por ejemplo, en el inicio de la vigésima carta, Plinio cita a Virgilio de manera explícita: "Aunque mi corazón se estremece al recordarlo... comenzaré” (Plinio el Joven, Epístolas XVI-I). Se observa la intención de ganar el efecto pasional de su relato al seguir la fórmula probada para referir un hecho dramático. Tanto la carta, el mensaje y el e-mail son formas de relato de actualidad porque sustituyen en su narración a los hechos acontecidos y en poco difieren del uso de fórmulas probadas en cuanto al efecto sensible de su efícacia patémica. Su individuación permite censar los mecanismos utilizados e identificar su eficacia pues en su reiteración, en su continua acción de re-proposición, se estandariza su uso y se refuerza su efectividad comunicativa.

\section{EL RELATO DE ACTUALIDAD EN EL TIEMPO}

El espacio, como medida del relato, supone su estrecha relación con el tiempo por la mutua dependencia al momento de materializar en un orden los recursos expresivos disponibles. A partir de lo que está pasando "en este momento" y lo que pasó en "ese momento", el espacio circunscribe el lugar y la duración de los hechos relatados y produce acciones consecuentes en ese mismo lugar o en otro, aun en una distancia temporal entre ellos. Una historia presente en las crónicas de la Conquista de México contiene un relato de actualidad en su momento histórico y en su funcionamiento como narración posterior para advertir la importancia del espacio en la construcción del sentido. Se trata de la información recibida por el Tlatoani azteca, Moctezuma II, sobre la existencia de los caballos desembarcados en Veracruz con las tropas de Hernán Cortés. Aunque en origen se trata de un experimento cognitivo realizado por Umberto Eco en su libro Kant e l'ornitorinco (1997), en dicho experimento se habla del efecto de un relato de actualidad de un suceso lejano en el espacio, pero conectado al presente del espacio donde se realiza la recepción. De esa manera, en su determinación del aquí y del ahora, el cronotopo será fundamental para lograr la interpretación de acuerdo con la función comunicativa 
asignada. Ese relato de actualidad es referido en diversas narraciones, revelándose los diversos tipos de tiempo a partir de un metatiempo del cual derivan otros tiempos: el biológico, el físico, el metafísico, el sagrado, el profano, el micro, el sincronizado y el personal (Hall, 1983). Para Moctezuma, el antecedente en la comprensión de los hechos por enfrentar, a partir de las narraciones contenidas en los relatos, le permitió conocer a su oponente antes del encuentro, trabajo semiótico determinante en el resultado final de la historia. Los relatos fueron disponiendo los elementos necesarios para la comunicación y la comprensión en el momento que se iban produciendo, pero también para la comprensión posterior del hecho histórico.

Los tipos de texto del relato de actualidad aparecieron de manera inmediata al desembarco español en la costa del Golfo de México (Todorov, 1982). Igualmente, los recursos comunicativos a disposición fueron inmediatos: traducción simultánea en diversas lenguas, información cartográfica, servicios de correo eficaces en amplias distancias, estrategias diplomáticas. Los relatos evidencian las impresiones de ambos lados de la cadena comunicativa en las direcciones de los polos opuestos: españoles e indígenas. Los tipos de relatos se han podido clasificar a partir también de sus autores: i) los conquistadores españoles contando los hechos de primera o segunda mano; ii) los indígenas que comunicaron en el momento cuyos relatos son descritos a la distancia de los hechos, y posteriores versiones realizadas por solicitud de los españoles, iii) los religiosos cuyos relatos retomaron los primeros y los ordenan en historias para narrar los hechos históricos acontecidos. El circuito comunicativo comprende la instancia receptora que determina su valor de gesta: los textos escritos por los conquistadores van dirigidos al público español. Los textos de los Cronistas, religiosos en su mayoría, difieren de los primeros y se dirigen a un público menos específico, aunque más universal, al incluir algunos la posición de los indígenas. Los textos pictográficos son el resultado de un mixto en su organización lingüística y visual, donde la escritura pictográfica sufre una occidentalización y, a su vez, funciona como reservorio de la memoria visual. Cada relato supone una estrategia de actualidad diversa, ya sea en el momento de su producción o en el momento de su recepción e incluso de su consumo (Cid Jurado, 1997). La Crónica de Fray Bernardino de Sahagún ejemplifica un relato de actualidad de la epidemia de viruela, enfermedad usada como arma biológica en la guerra contra los aztecas. 


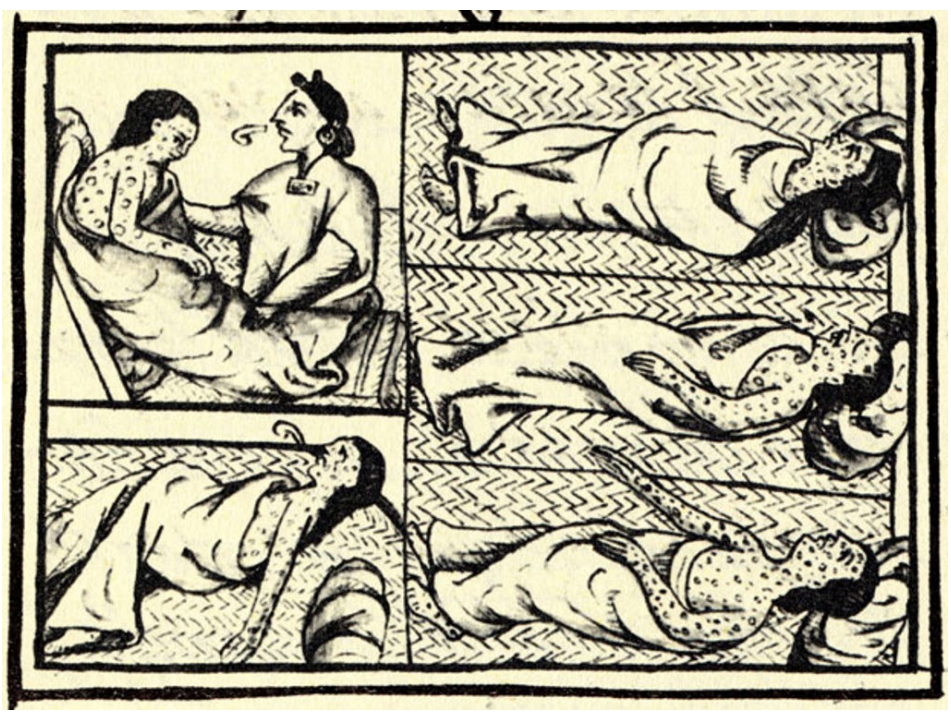

Imagen 1. Relato visual de la epidemia de cocoliztli en México Tenochtitlan. B. de Sahagún Códex Laurenziano Mediceo Palatino 218 219, 220.1576: Cap. 29, Fo. 53

El relato visual (Imagen 1) representa gráficamente los efectos de la viruela en la población. La imagen encapsulada, además de concentrar la imagen visual del relato, llama la atención en la visión de los religiosos sobre el punto de vista de los indígenas. Del "yo vi" al "yo escuché" aparecen dentro de los hechos narrados como pruebas de la autenticidad y la veracidad de lo relatado.

\section{EL RELATO DE ACTUALIDAD DE LA PANDEMIA EN SU FUNCIÓN SOCIAL}

El concepto de actualidad abarca un tiempo y un espacio para devenir en relato y ambos son necesarios en la tarea de comunicar un hecho contemporáneo actual en diversas épocas. La lectura al presente de los signos procedentes del pasado en su relación con los hechos naturales referidos, son recurso para construir la memoria y proceden a conservarla al ser narrados desde el espacio donde se han producido los hechos narrados (Pomian, 1999). La interacción entre componentes dota de valor a los relatos como vehículos por la información contenida. La condición de verdad se convierte en logro del relato si se refiere a lo sucedido, al momento de su narración, con el propósito de ordenar y presentar los hechos, incluyéndose las condiciones de fruición en un nuevo espacio de interpretación (Momigliano, 1983).

Para entender el relato de actualidad a partir de las condiciones prefijadas en la interpretación, la obra de Giovanni Bocaccio, Il Decamerone, es una obra clásica donde se registran las historias posteriores a la "mortifera pestilenza". El autor hace uso manifiesto del relato y lo dota de un fin social y de una tarea cognitiva. Se trata de ayudar a comprender los hechos acontecidos, al aprovechar las características propias de una narración, para mostrar una coherencia y cohesión narrativa acordes a la presentación de 
los hechos relatados. Tales acontecimientos, no obstante su condición de ficción literaria, se reconocen como hechos realmente sucedidos por ser más relevante su exposición curativa ante el sufrimiento. En el goce del placer narrativo, en la fruición del relato, se halla el elemento enriquecedor para mitigar el sufrimiento de los efectos de una pandemia, tal como se observa en este pasaje:

Ma non voglio per ciò che questo di più avanti leggere vi spaventi, quasi sempre tra sospiri e tra le lacrime leggendo dobbiate trapassare. Questo orrido cominciamento vi fia non altrimenti che a' camminanti una montagna aspra et erta, presso la quale un bellissimo piano e dilettevole sia riposto, alla quale un bellissimo piano e dilettevole sia riposto il quale tanto più viene lor piacevole, quanto maggiore è stata del salire e dello smontare la gravezza (Boccaccio, 1857: 6) ${ }^{1}$.

Es posible señalar una tarea ulterior en el relato de actualidad que deriva de una necesidad cognitiva, basada en la jerarquización de los hechos registrados en la memoria de los medios y al interior del macro-relato. La conexión entre manifestación textual y efecto en el receptor forma parte de las estrategias frecuentes en los relatos de ficción. Gracias a esas condiciones se da una relectura de los sucesos y de los protagonistas, al asignar los valores éticos con los cuales los hechos relatados serán relacionados. Un relato de actualidad debe ofrecer como primera instancia una versión sintética necesaria para las lecturas posteriores, brindar una línea directriz para explicar el evento acaecido en ese momento y dirigido a su posterior comprensión, actualizándolo en el marco de una contemporaneidad para las lecturas por venir. Los principios rectores serán: 1) la autenticidad; 2) el impacto en la memoria popular; 3) el uso de recursos para recrear o reconstituir el hecho auténtico, el hecho real, desde su actualidad. Las condiciones propias de un relato de actualidad son vigentes en sus versiones y recursos actuales, su forma corresponde a su función comunicativa y el proceso cognitivo de lectura garantiza las condiciones de verosimilitud de su conformación narrativa.

\section{EL RELATO DE ACTUALIDAD EN SU FUNCIONAMIENTO SEMIÓTICO}

Si el relato de actualidad se activa por medio de la puesta en funcionamiento del mecanismo interpretativo intrínseco en su propia estructura, su condición semiótica alerta sus formas de operar. Una de las perspectivas teóricas más importantes resalta algunas cualidades narrativas en los ejemplos elegidos: vislumbrar la puesta en marcha de una doble valencia, pues funciona como punto de llegada y al mismo tiempo como vehículo para acceder a un determinado significado. La actualidad se busca como condición

\footnotetext{
1 "Pero no quisiera como consecuencia de lo que más adelante vais a leer os espante, casi siempre entre suspiros y entre lágrimas, al continuar la lectura tenéis que continuar. Este hórrido comienzo os sea, no de otra manera, que como a los caminantes les resulta una montaña, hirsuta y escarpada, en la cual un hermosísimo y placentero paso es respondido, el cual mientras más agradable se muestra, mayor habrá sido la escalada y el desmontar de su gravedad" (Boccaccio, 1857: 6).
} 
determinante en el relato y contiene además lo que es actual. De esa manera, consiste en ser el espacio de lo sucedido y el espacio desde donde se observa lo que sucedió, pero es también el tiempo relatado y el relato de lo que ha sucedido en ese momento. La tarea de encapsular el hecho y volverlo propicio para ser comprendido, evaluado y valorado, lo circunscribe y lo dota de un significado finito, con límites incluso hermenéuticos. Cada relato en esa tarea es dotado de una significación inamovible e incuestionable, pues los valores refrendados en su narración quedan dispuestos para ser contados por su coherencia y su cohesión estructural, aún sin incorporar o agregar, ni mucho menos cuestionar el significado en ellos contenido.

No obstante, el relato de actualidad puede ser vehículo de algo falso por las condiciones de su estructura semiótica y se debe principalmente a la exigencia de responder a la inmediatez de los tiempos, al uso de la sustitución sígnica —al estar en lugar de un hecho acaecido sin requerir de una comprobación directa-, a la autopsia, a la imposibilidad de saber la condición de verdad del hecho al momento de referir su contenido, a las condiciones de ficción propias de un relato y a la suspensión de la incredulidad en una "caridad interpretativa" lograda al inicio de una estrategia para elaborar el relato. En suma, la semiótica del relato releva la importancia de una función ulterior consistente en explicar el qué, el porqué y el cómo, resumido en su efecto, según Umberto Eco (1985), en "È vero, eravamo e siamo ancora così..." (Es verdad, éramos y somos todavía de ese modo).

\section{REFERENCIAS BIBLIOGRÁFICAS}

BAJTín, M. (1989). Teoría y estética de la novela. Madrid: Taurus.

Bloch, M. (1949). Apologie pour l'historie ou métier d'historien. París: A. Colin.

BocCACCIO, G. (1857). Il Decameron. Firenze: Felice Le Monnier.

BREMOND, C. (1966). "La logique des possibles narratifs". Communications 8, 70-66.

CID JURADO, A. (1997). "Un cervo chiamato cavallo". Dattiloscritto. Università di Bologna.

COURTÉs, J. (1976). Introduction à la sémiotique narrative et discursive. Paris: Hachette. Eco, U. (1979). Lector in fabula. Milano: Bompiani. (1985). 30 anni di costume. Milano: L'Espresso. (1997). Kant e l'ornitorinco. Milano: Bompiani.

Greimas, A. J. (1970). Du sens. Essais sémiotiques. Paris: Seuil.

Hall, E. T. (1983). The dance of life. The other dimension of time. New York: Anchor Books.

JEDLOSWKI, P. (2007). "L'importanza del destinatario. Pratiche narrative, vita quotidiana, esperienza: uno sguardo sociologico". En Narrazione ed esperienza. Intorno a una semiotica della vita quotidiana, G. Marrone, N. Dusi e G. Lo Feudo (eds.), 81-91. Roma: Meltemi. 
KerCKHOVE, D. DE (1997). Connected intelligence. The arrival of the web society. Toronto: Somerville House Books.

Pomian, K. (1999). Sur l'histoire. Paris: Gallimard.

LEVY, P. (1994). L'intelligence collective. Pour une anthropologie du cyberspace. Paris: La Découverte.

LozANO, J. (1987). El discurso histórico. Madrid: Alianza Universidad.

Plinio (el joven) (2007). Epistolario (Libros I-X). Panegírico del emperador Trajano. Madrid: Cátedra.

Momigliano, A. (1983). Problèmes d'historiographie ancienne et moderne. Paris: Gallimard.

Ricoeur, P. (1983). Temps et récit. Tome I: L'intrigue et le récit historique. Paris: Seuil. RhEINGOLD, H. (2004). Smart Mobs: Multitudes Inteligentes. Barcelona: Gedisa.

SAHAGÚN, B. DE (1995 [1576-1577]). Historia General de las cosas de la Nueva España. Códex Laurenziano Mediceo Palatino 218 219, 220. Facsimil. Firenze: Giunti. Todorov, T. (1982). La conquête de l'Amérique, la question de l'autre. Paris: Seuil.

VILCHES, L. (2017). Diccionario de teorías narrativas. Cine, Televisión, Transmedia. Barcelona: Caligrama.

El/la firmante del artículo se responsabiliza de las licencias de uso de las imágenes incluidas.

Fecha de recepción: 07/02/2021

Fecha de aceptación: 05/05/2021 